\title{
A NOVEL METHOD TO ESTIMATE ECONOMIC REPLACING TIME OF TRANSFORMER USING MONTE CARLO ALGORITHM AND ANN
}

\author{
Mehdi Zareian JAHROMi ${ }^{1}$, M.hossein MEhrabanJahromi ${ }^{2}$, MohSEN \\ TAJDINIAN $^{3}$, MeHDi AllahbaKHSHI ${ }^{4}$ \\ 1, Department of Electrical Engineering, Amirkabir University of Technology, No. 424, \\ Hafez Avenue, Tehran 1591634311, Iran
}

\section{2, Department of Electrical Engineering,Science and Research Branch, Islamic Azad University,Tehran,Iran.}

\author{
3,4, School of Electrical and Computer Engineering, Shiraz University, Shiraz, Iran \\ Im.jahromi@aut.ac.ir, ${ }^{2} m h . m e h r a b a n @ s r b i a u . a c . i r,{ }^{3}$ tajdinian.m@shirazu.ac.ir, \\ 4allahbakhshi@shirazu.ac.ir
}

*Corresponding author: Mehdi Zareian Jahromi (m.jahromi@aut.ac.ir)

(Received: $9^{\text {th }}$ Feb 2017; Accepted: $5^{\text {th }}$ June 2018; Published on-line: $1^{\text {st }}$ Dec 2018)

https://doi.org/10.31436/iiumej.v19i2.793

\begin{abstract}
A hybrid method for developing a more principled approach is presented to determine the life expectancy of transformers. The approach is constructed on an economic analysis of the transformers operational characteristics in combination with the technical issues incorporated in the decision process. In this method, firstly life time of transformer is estimated using a hybrid method based on Monte Carlo algorithm and artificial neural network. Also Pareto distribution function is applied to consider health history of transformer and uncertainty in DP behavior of transformer. In the next step, a method is proposed in order to estimate economic replacement time of transformer. This method is based on the well-known bathtub failure model, containing repairs and scheduled maintenance, in order to achieve at a more economically aim replacing decision. This aim is obtained in part by considering the uncertainty intrinsic in transformer failures and the corresponding discontinuations in power. In essence, this method organizes a decision support system for determination the life expectancy of a transformer. Simulation results show the high accuracy and functionality of the proposed approach in estimating economic replacing time of the Transformer.
\end{abstract}

ABSTRAK: Kaedah hibrid bagi membangunkan cara yang lebih berprinsip telah dibentangkan bagi menganggarkan jangka hayat sesebuah transformer. Kaedah ini telah dibuat dengan cara analisis secara ekonomi terhadap karakter operasi transformer melalui gabungan isu teknikal dan proses keputusan. Melalui kaedah ini, perubahan masa hidup telah dianggarkan menggunakan kaedah hibrid berdasarkan algoritma Monte Carlo dan rangkaian saraf jadian. Fungsi agihan Pareto juga telah digunakan bagi mengambil kira sejarah kesihatan transformer dan ketidak pastian kelakuan DP pada transformer. Langkah seterusnya adalah melalui anggaran ekonomi masa penukaran transformer ini. Kaedah ini berdasarkan pada model kegagalan tab mandi yang terkenal, mengandungi jadual pembaikan dan penyelenggaraan, bagi mencapai sasaran keputusan tukaran yang lebih ekonomi. Sasaran ini dicapai dengan menimbang kepentingan ketidakpastian pada kegagalan transformer dan tenaga yang ada. Intipatinya, kaedah ini menyusun sistem 
sokongan keputusan bagi mencapai jangka hayat transformer. Hasil simulasi menunjukkan ketepatan yang tinggi dan kesesuaian cadangan kaedah ini dalam menganggarkan masa penukaran transformer secara ekonomi.

KEY WORDS: Economic Replacing Time of Transformer, Monte Carlo Algorithm, Neural Network and Pareto Distribution.

\section{INTRODUCTION}

In general, the asset management of Transformer is noticed to be one of the most important areas of management regarding power system equipment. Assessing the assumed term when transformers will require to be changed, demonstrates a very significant asset management activity, particularly in consideration of the current aging status of the throughout power system network. The immense investment shown by power transformers and the significant duty they have in the power network are other factors that confirm the significance of the selection of suitable replacement times. since technical issues and economic factors are involved in aforementioned timing, management must be involved in decisions. Several tests including tests for moisture content [1, 2]; oil gassing tendency [3, 4]; and partial discharge (PD) [5] can be carried out for obtaining data about a transformer technical performance. Other tests, such as the polymerization degree (PD) and the retained tensile strength of the paper insulation, cannot be carried out because they need disposal to the insulating paper into the transformer. As a result, complete test results would prepare a generic evaluation of the circumstances of the transformer, but they would not concede any quantitative data regarding its life anticipation. Obvious examples are transformers that have prepared years of service and as a result they are diagnosed to possess significant amounts of sludge in the oil. In the case of PD in oil-immersed transformers the PD intensity can change significantly with time, so that an enhanced PD intensity require not necessarily imply impendent failure, as a result, it is not possible to approximate their life expectancy in terms of PD intensity. Thus, it is obvious that diagnostic tests supply effective information regarding the condition of transformers and can disclose problems, however, they do not yield the type of deterministic quantitative data regarding life expectancy that is needed for the future planning of power network. As the physical life of a transformer increases, the probability of its failure increases due to the aging of its components, and as a result it will be increased the costs of power interruptions and repairs of power transformers.. From economic point of view it is wisely to replace a transformer before it reaches to its physical end of life [6]. making decisions for transformers replacement in suitable time from economic point of view have appertained the operating and maintenance costs of the transformer[7-10]. However, the algorithm of economic replacement, as proposed in [7-10], have not used the realistic parameters for transformers. To be more precise, the impact of the failure rate of transformer on operating and maintenance costs has not been considered [11-13]. Likewise, the economic replacement approaches presented in [7-10] do not consider the uncertainties intrinsic in rates of failure and repair. The asset annual unavailability, the cost of interruptions and repairs are the factors that are affected from the aforementioned uncertainties. The interruptions cost is itself not taken into account, and the annual present worth computed for the transformer is based on a depreciation method that 
does not combined the different stages in the life of a transformer. A thermal model was suggested to determine the total transformer lifetime, the expected time to the end of the life of the transformer, and as a result, the suitable time for transformer replacement $[14,15]$. However, any economic factors such as operating and maintenance costs have not been taken into account in aforementioned type of approach. moreover, these approaches also do not address the extra costs regarding interruptions [16, 17], and repairs [18] that is caused by the enhanced rate of failure when transformers are utilized in the course of their wearout stage. it can be noted that changing a transformer before its estimated thermal lifetime is sometimes more inexpensive than Spending such high repair costs.

The main purpose of the research study which it will be discussed in this paper is creating a reliable decision support system to determine from an economic aspect the appropriate time to replace power transformers, considering the consequences of all physical stresses that influence transformers. As mentioned,one of the most important issues to estimate transformer life time is study of Aging insulating of transformer during operation lifecycle, because transformer insolation is not easily replaceable or repairable. On the other hand, aging insolation depends on amount of chemical furfural contained in transformer oil where estimation of furfural is very difficult and costly. Therefore this study uses a heuristic method based on artificial neural network to estimate furfural contained in transformer oil. Afterwards, this paper proposed a hybrid method based on Pareto distribution and Monte Carlo search algorithm to estimate transformer end life. Finally an economic idea is proposed to estimate economic replacement time of transformer. The procedure of process is described as detail in algorithm and implementation section. The new features of the proposed replacement method are as follows:

1) estimating of amount of furfural utilizing DGA data and ANN ;

2) determining of DP value of the transformer using ANN output;

3) preparing health history using pareto distribution in order to take the uncertainty of actual behavior of DP value into account ;

4) applying monto carlo search algorithm to estimate end life of transformer;

5)applying new economical method based on the comparsion between aged and young transformer to determine the economic replacement time;

The rest of this paper includes of four sections: Section II contains the background of the Considerations of Proposed Algorithm for life-time estimation in power transformer, Section III presents the proposed approach and main concept of techno-economic utilized in this research, section IV demonstrates the results of the practical case study and section $\mathrm{V}$ provides the conclusions.

\section{CONSIDERATION OF PROPOSED ALGORITHM AND IMPLEMENTATION}

As discussed in [16] the failure phenomenon of the transformer has a probabilistic nature which is assessed mainly by three parameters: design, aging, and external triggering events. As a result, end-of-life modeling intends to expand relationship between the aging 
conditions and transformer inherent dielectric properties as well as transformer thermal life, represented as the service years for losing the mechanical strength of solid insulation under operational conditions [19].

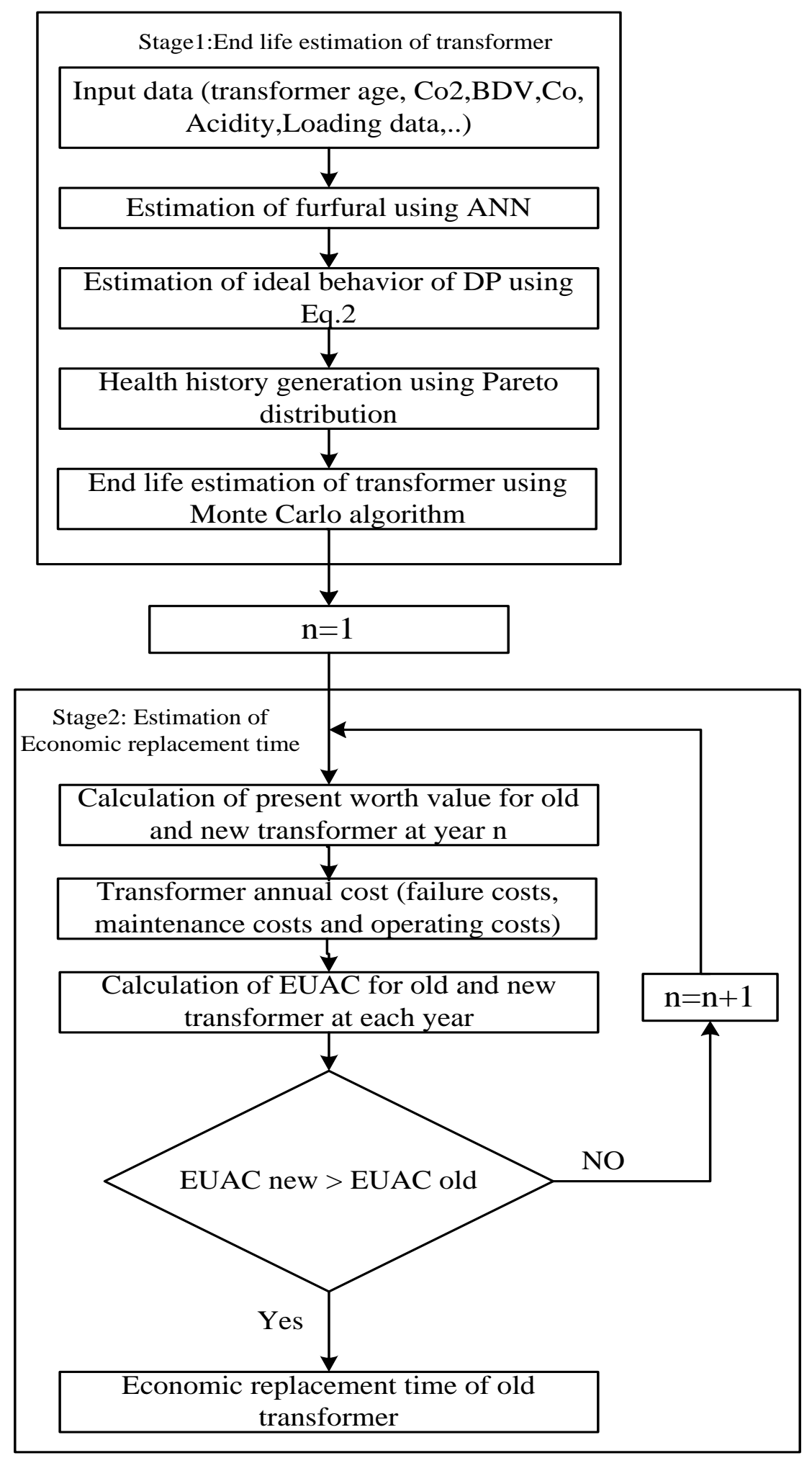

Fig. 1. The calculation procedure of economic replacement time of transformer. 
As mentioned, the aim of the proposed methos is estimating the end of normal life time and economic replacement time of transformer when it is considers health history of the transformer. Fig .1 shows economic algorithm of transformer replacement time from the beginning to the end. The proposed method have two main stages. In the first stage of this algorithm, ANN has been utilized for estimating the amount of furfural to determine the transformer DP value. Also, after health history has been created using Pareto distribution function, utilizingMonte Carlo search algorithm end life of transformer can be estimated. In the second stage, an economic method has been proposed which compares economic valuation of aged transformer with young transformer to determine economic replacement time of old transformer.

\section{DATA INITIOALIZATION AND FUNDAMENTAL OF PROPOSED TECHNO-ECONOMIC CONCEPT}

\subsection{Estimation of Furan Content}

The impurities in the oil of transformer such as oxidation and water content are measured by breakdown voltage (BDV). one of the significant sources of to enhance the water content in transformer oil is Cellulose aging process. As a result, the oil BDV and furan content in the oil of transformer are correlated. Also because of paper and oil degradation, water is generated in the transformer oil . the strength of dielectric is decreased as a result of creating high stressed areas in the insulating substance which catalyzes the aging process. Thus, from paper insulation degradation point of view, water can advance and result in the insulation degradation .because of increasing hydrolysis of cellulose paper, acidity in transformer oil causes the degradation of paper insulation . the latter process eventually leads to generate glucose which transform to furanic combinations in transformer oil. Utilizing disolved gas analisys, concentrations of $\mathrm{CO}$ and $\mathrm{CO} 2$ can be measured. One of the effective index to evaluvate of cellulose paper thermal degradation is The concentrations of $\mathrm{CO}$ and $\mathrm{CO} 2$ gases. As a result, $\mathrm{CO} 2 / \mathrm{CO}$ ratio is utilized in utilities as a index for paper insulation degradation detection in transformers. it should be noted that both $\mathrm{CO}$ and $\mathrm{CO} 2$ are created in transformer oil as a result of the destruction of the transformer oil and not merely cellulose paper, which decreaes the reliability of these gases to evaluvate the solid insulation substance of the power transformer.

In this paper, back propagation neural network is used to estimate furfural. Back propagation networks are multi-layer networks with nonlinear transfer functions. Back propagation networks are used to approximate a function, finding the relationship between inputs, and outputs and classification of inputs. Also they usually have one or more hidden layers of neurons with a Sigmoid transfer function and an output layer which mainly uses a linear function. Fig. 2 shows a two-layer Tansig/Purelin network architecture which includes a hidden layer and an output layer with back propagation structure. This network can be used to approximate any function with a limited number of discontinuities [20]. 


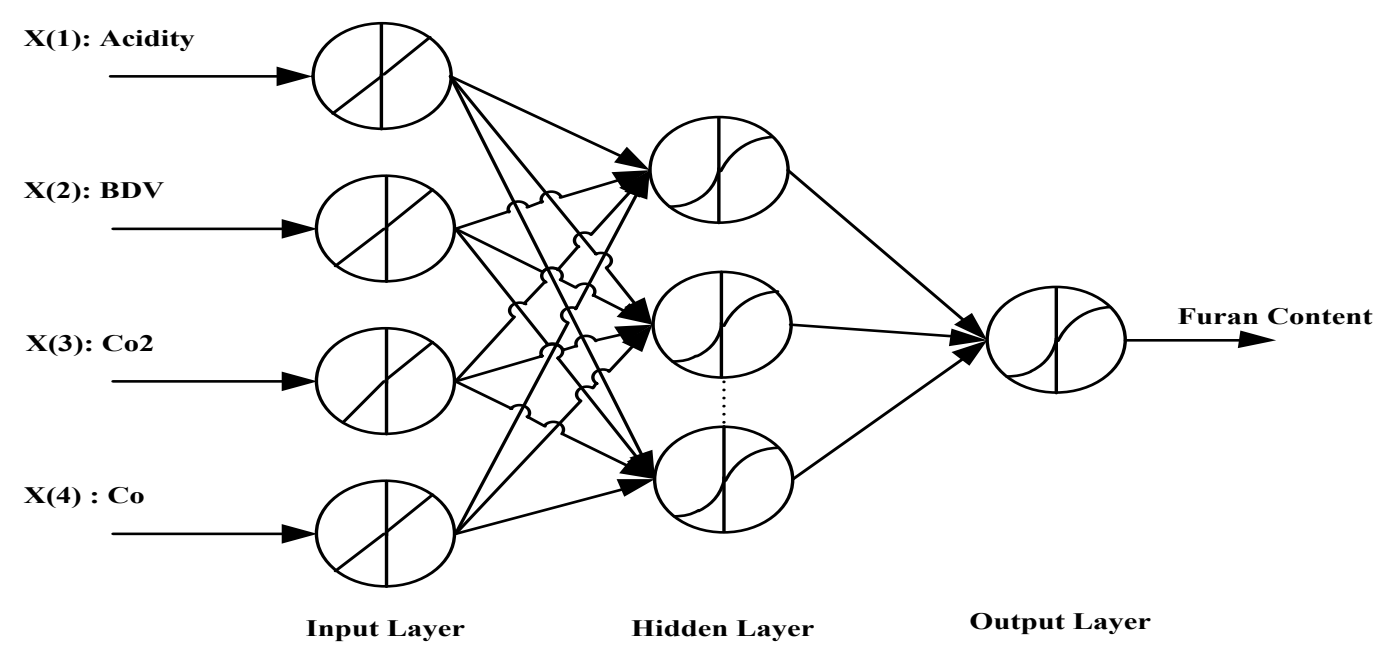

Fig. 2. The back propagation network structure with 4 input.

In order to train the neural network, 2040 training patterns are used. 1734 patterns are used as training patterns and 306 patterns are used for testing the neural network, where acidity, Break down voltage (BDV), $\mathrm{Co} 2$ and $\mathrm{Co}$ are used as inputs and the furfural is considered as the outputs of the neural network.

\subsection{End life Estimation of Transformer}

As mentioned in previous section, transformer end life depend on aging insolating which is analyzed by the degree of polymerization (DP) according the following equation [21]:

$$
D P\left(t_{0}\right)=\frac{2.5-\log [F]}{0.005}
$$

Therefore, the following equations can be written to estimate remaining life time of the transformer in the ideal case [21]:

$$
\begin{aligned}
& \frac{d D P(t)}{d t}=-k(t)[D P(t)]^{2} \\
& D P(t)=\frac{D P\left(t_{0}\right)}{1+D P\left(t_{0}\right) \int_{t 0}^{t} k(\tau) d \tau} \\
& k(t)=A \exp \left(-\frac{E_{a}}{R_{g} T(t)}\right)
\end{aligned}
$$

Where $T(t)$ is Hot spot temperature of transformer which can be defined as follows:

$$
T(t)=T_{a}(t)+\Delta T_{T o}(t)+\Delta T_{2}(t)
$$

Where $\Delta T_{T o}(t)$ is Increasing oil temperature in the upper part of the transformer which is depended on load changes. Also, (6) is used to consider effect of Moisture and oxygen on aging insulating [22]:

$$
\text { Normal Life }=\frac{\text { Normal Life at }\left[.5 \% \mathrm{H}_{2} \mathrm{O}\right]}{2 \times \% \mathrm{H}_{2} \mathrm{O}}
$$


Where $\mathrm{H}_{2} \mathrm{O}$ is the amount of moisture in insulation system therefor (6) estimate transformer end life in ideal state. In the next step, Pareto distribution is used to generate health history of transformer and model the uncertainty in ideal behavior of transformer lifetime. Parameters of Pareto probability distribution function which is used in this study are defined in appendix section. Fig.3 shows ideal and Non-ideal behavior of DP curve when Pareto distribution is applied to ideal curve of DP.

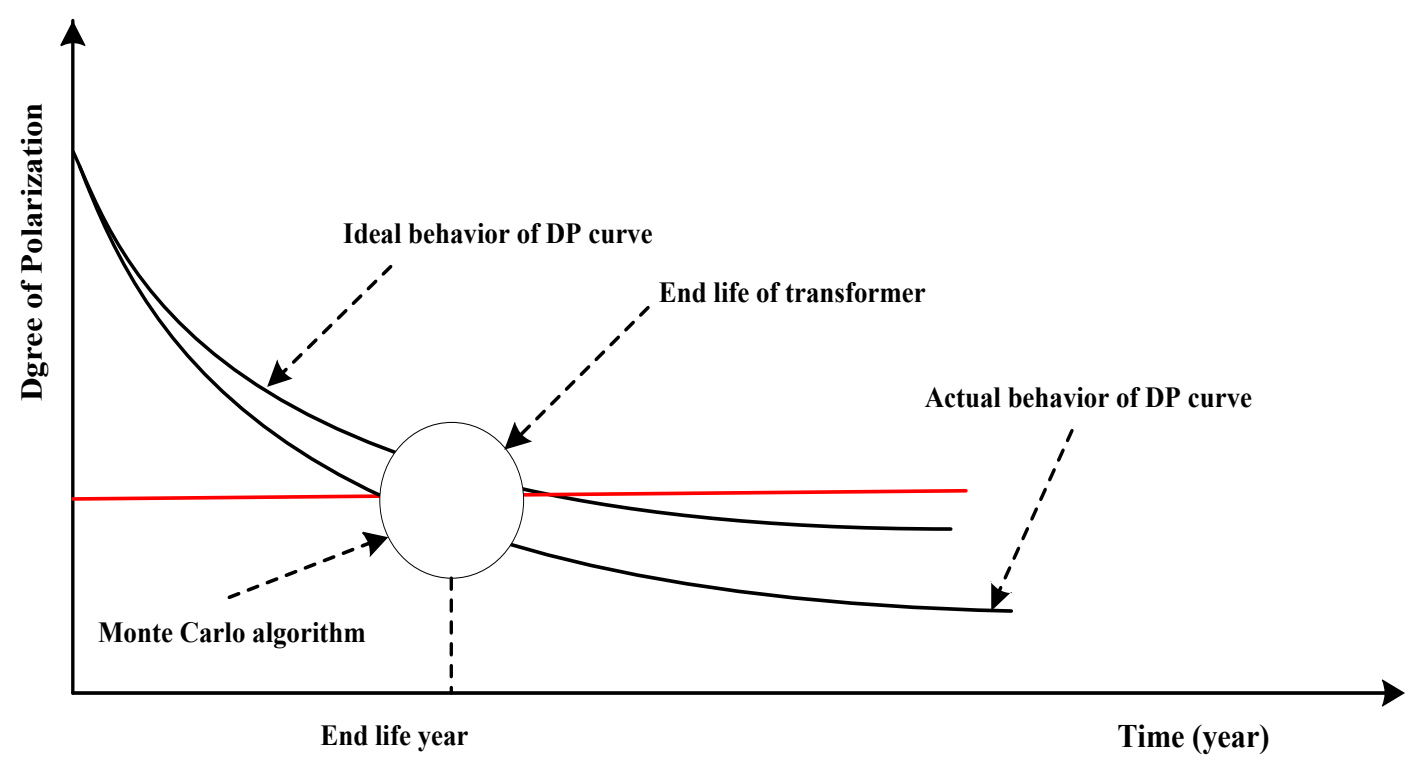

Fig. 3. Estimation of end life of transformer considering actual behavior of DP curve.

Afterward, as can be seen in Fig. 3, in order to consider the uncertainty of age searching on Pareto distributed curve Monte Carlo algorithm is used to predict the failure probability of the transformer when DP curve of transformer intercept threshold DP of transformer at each step time of simulation. Monte Carlo which is used in this research have the following stages [23]:

1) Compareing the history curve of DP with its ideal form to extract deviation of Pareto distribution data at each time step of simulation.

2) Fitting the extracted data on Pareto distribution curve to estimate parameters of Pareto function.

3) Predicting the deviation of ideal DP curve in the future time by estimated Pareto function.

4) Finding the Confluence of threshold DP and the area between ideal and deviated curve of DP using random search of Monte Carlo algorithm.

\subsection{Economic Replacement Time of Transformer}

This section proposes a novel algorithm which considers all details to calculate economic replacement time of transformer because it is different from failure time of transformer. Actually, Economic value of transformer per year is obtained from calculation of operating costs of transformer in each year of operation. According to [24], economic valuation of transformer has five steps: 
1) Data collection

2) calculation of present worth value of transformer

3) Transformer annual cost (failure costs, maintenance costs and operating costs)

4) calculation of EUAC

5) Prioritizing transformers

Therefore, in order to calculate economic replacement time of transformer, firstly, economic valuation of old transformer and new transformer are calculated at each remaining years of their life time. Afterward, the intersection of economic valuation curve of old transformer and new transformer is a suitable time for replacement of old transformer which is shown in Fig. 4. In the other words, after this time, economic valuation of old transformer is less than new transformer.

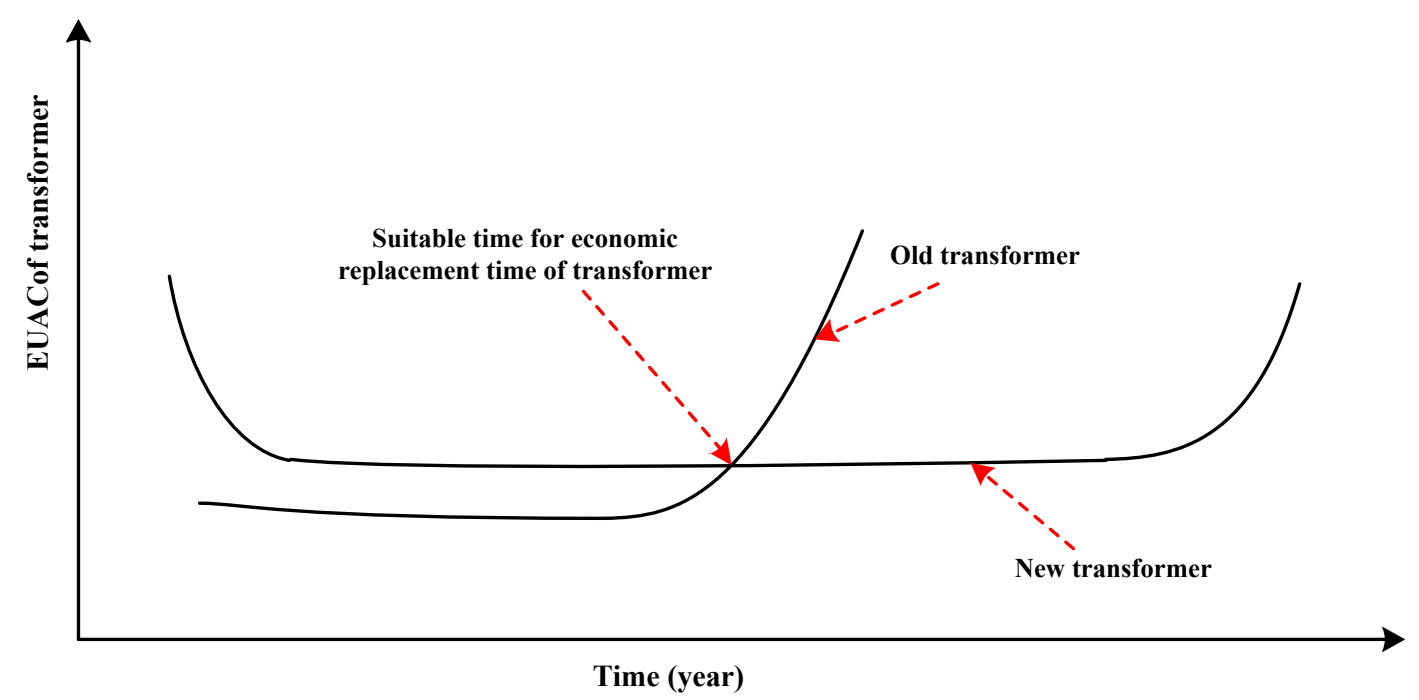

Fig. 4. Estimation of suitable time for economic replacement time of transformer.

The most important step in proposed algorithm is calculation of present worth value transformer and calculation of annual cost of transformer. On the other hand bathtub curve is necessary to calculate annual cost of transformer [12, 13, 25]. Also Monte Carlo algorithm is applied to model uncertainties of transformer such as unexpected output and repairing time [23]. All part of proposed algorithm are described as a detail in[24].

\section{CASE STUDY}

In order to verify the performance of proposed method forty transformers that belong to distribution Company have been utilized in the paper. The required training and testing data utilized in the ANN model has been captured from maintenance records of transformers for transformers with voltage ratings of $420 / 36 \mathrm{kV}, 245 / 11 \mathrm{kV}$ and various ages. The mineral naphthenic oil is the type oil utilized in the investigated transformers. Table 1 illustrates samples of the obtained data of oil testing which has been used in the research study. As can be seen in Table 1, the results of the oil testing of the transformer provide a comprehensive range of transformer oil status. 
Table 1: Samples of the oil data used in this study to predict furan content in transformer oil

\begin{tabular}{|c|c|c|c|c|c|c|c|c|}
\hline $\begin{array}{c}\text { TR } \\
\text { Number }\end{array}$ & $\begin{array}{c}\mathrm{CO} \\
(\mathrm{ppm})\end{array}$ & $\begin{array}{c}\mathrm{CO} 2 \\
(\mathrm{ppm})\end{array}$ & $\begin{array}{l}\text { TCG } \\
(\mathrm{ppm})\end{array}$ & $\begin{array}{l}\text { TDCG } \\
(\mathbf{p p m})\end{array}$ & $\begin{array}{c}\text { Water Contetnt } \\
\text { (ppm) }\end{array}$ & $\begin{array}{l}\text { Acidity } \\
\text { (KOH/g) }\end{array}$ & $\begin{array}{l}\text { BDV } \\
(\mathrm{Kv})\end{array}$ & $\begin{array}{c}\text { Furan } \\
\text { Content } \\
\text { (ppm) }\end{array}$ \\
\hline T1 & 393 & 4559 & 746 & 5323 & 39 & 0.54 & 28 & 17.96 \\
\hline $\mathbf{T} 2$ & 193 & 9128 & 322 & 9350 & 35 & 0.14 & 23 & 14.11 \\
\hline T9 & 298 & 2710 & 342 & 3052 & 21 & 0.19 & 54 & 4.23 \\
\hline T15 & 347 & 1816 & 361 & 2177 & 7.0 & 0.10 & 57 & 3.06 \\
\hline T16 & 229 & 1230 & 266 & 14.96 & 13.0 & 0.11 & 60.0 & 2.81 \\
\hline T26 & 374 & 2836 & 577 & 3413 & 12 & 0.03 & 89.9 & 1.57 \\
\hline T36 & 58 & 1775 & 129 & 19.04 & 14 & 0.04 & 58.0 & 0.04 \\
\hline T37 & 122 & 2386 & 190 & 3.26 & 10 & 0.04 & 78 & 0.38 \\
\hline T40 & 66 & 1147 & 78.0 & 1225 & 9.0 & 0.02 & 77 & 0.19 \\
\hline
\end{tabular}

\subsection{Furfural Estimation}

In this section, the ANN which is explained in section 3.1, it is trained by the LevenbergMarquardt training algorithm at 1000 epochs to estimate furfural of oil transformer. This study considers $60 \%$ of data for training, $20 \%$ for validation and $20 \%$ for testing. As can be seen in fig. 5, after training the proposed network final mean square error for training, validation and test are less than $0.50 \times 10^{-4}$ but the best validation performance is $1.3688 \times 10^{-5}$. After completing the training and testing procedure of ANN, it is applied to the proposed approach.

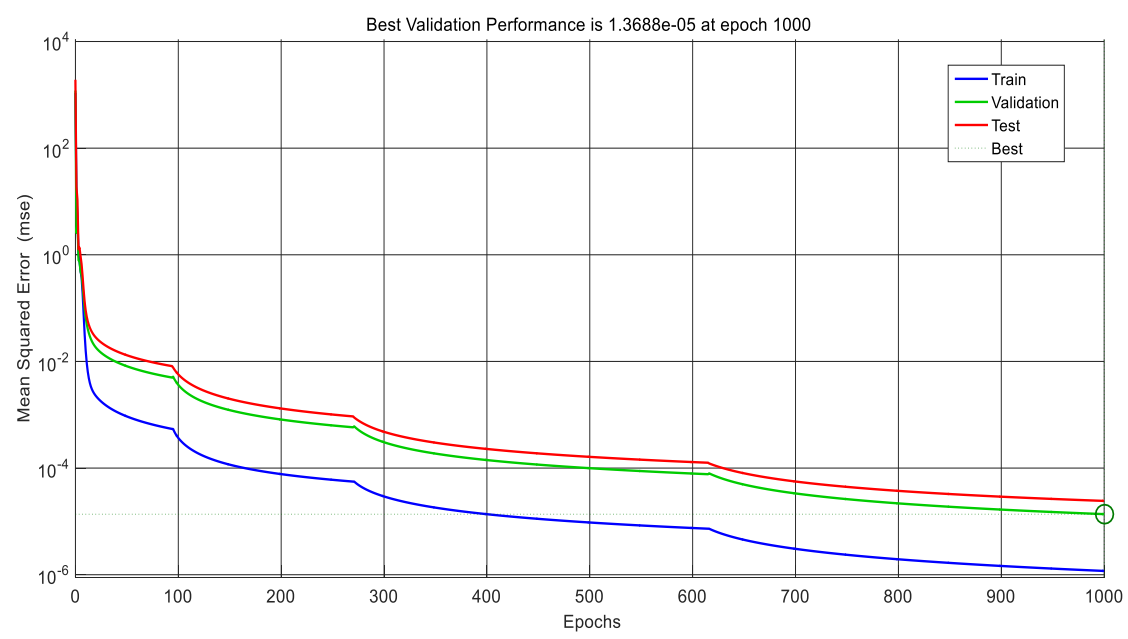

Fig .5. Mean squared error curve for training of proposed ANN at each epoch. 
Finally, proposed ANN predicts value of 0.20 for furfural for inputs values of below which is shown in Table 1. After estimation of furfural, remaining life time of the transformer is estimated using Monte Carlo algorithm and Pareto distribution function which will be discussed in the following section.

\subsection{Remaining Life Time}

In this section, remaining life time of transformer is estimated using Eqs (1)-(6). Fig. 6 shows ideal and actual behavior of DP curve. As can be seen in Fig. 6, the actual behavior of DP curve of aging transformer is different form ideal curve form the first to the fifth year when the aging transformer has five years old. Therefore distribution of deviation in DP will be extracted by comparing history curve and ideal curve of DP, which is shown in Fig. 7. In the next step, according to Fig. 8, the expected behavior of actual DP for the past years is predicted using Pareto distribution function when threshold DP is 250. Finally, Monte Carlo search algorithm finds the confluence of threshold DP and the area between ideal and actual curve of DP an d it predicts the transformer will be failed after 13.805 years which is shown in Fig.9.

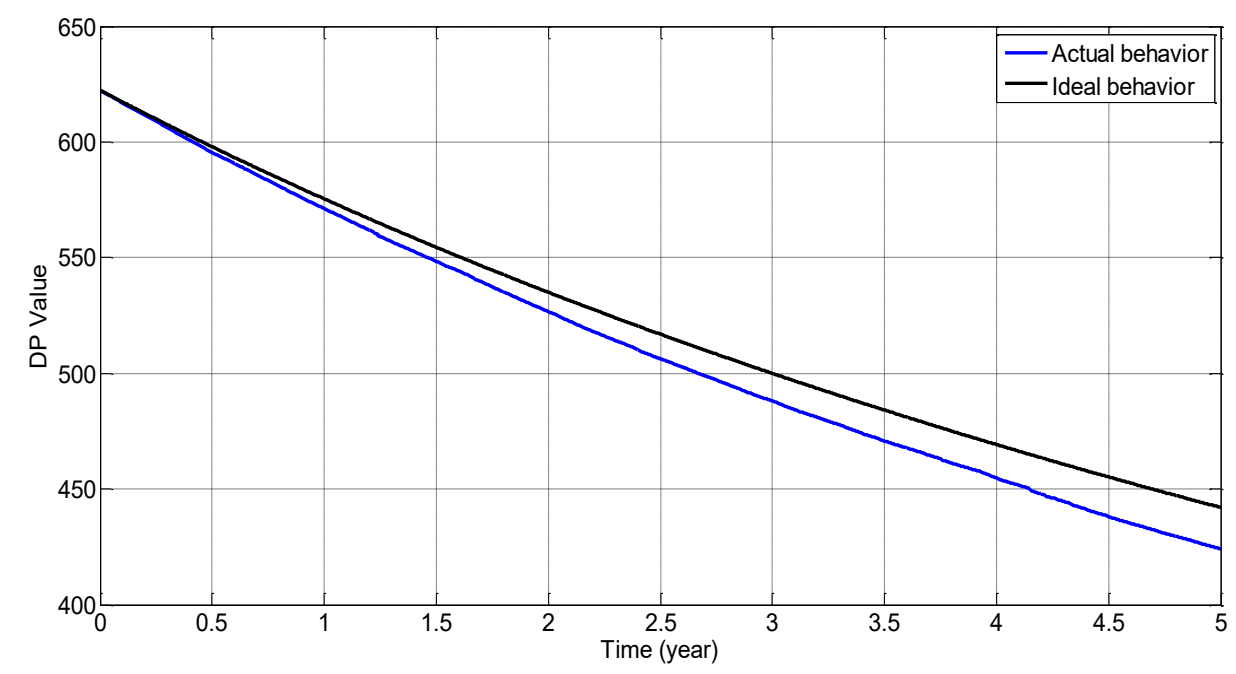

Fig6. Comparison Compare of Ideal and actual behavior of DP.

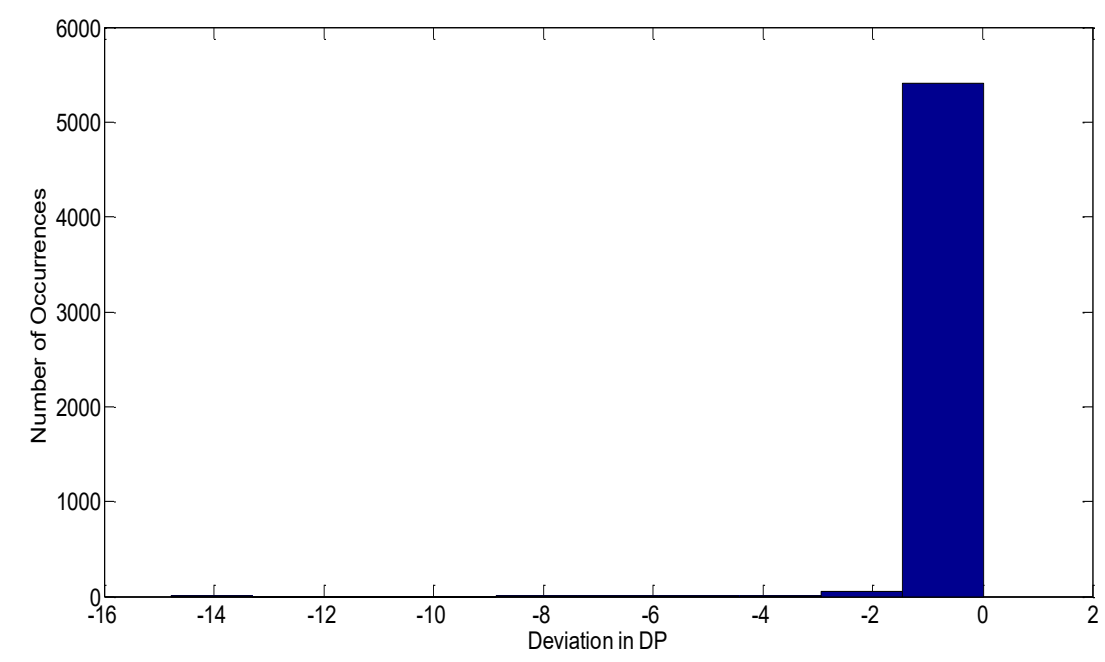

Fig. 7. Distribution of deviation in DP. 


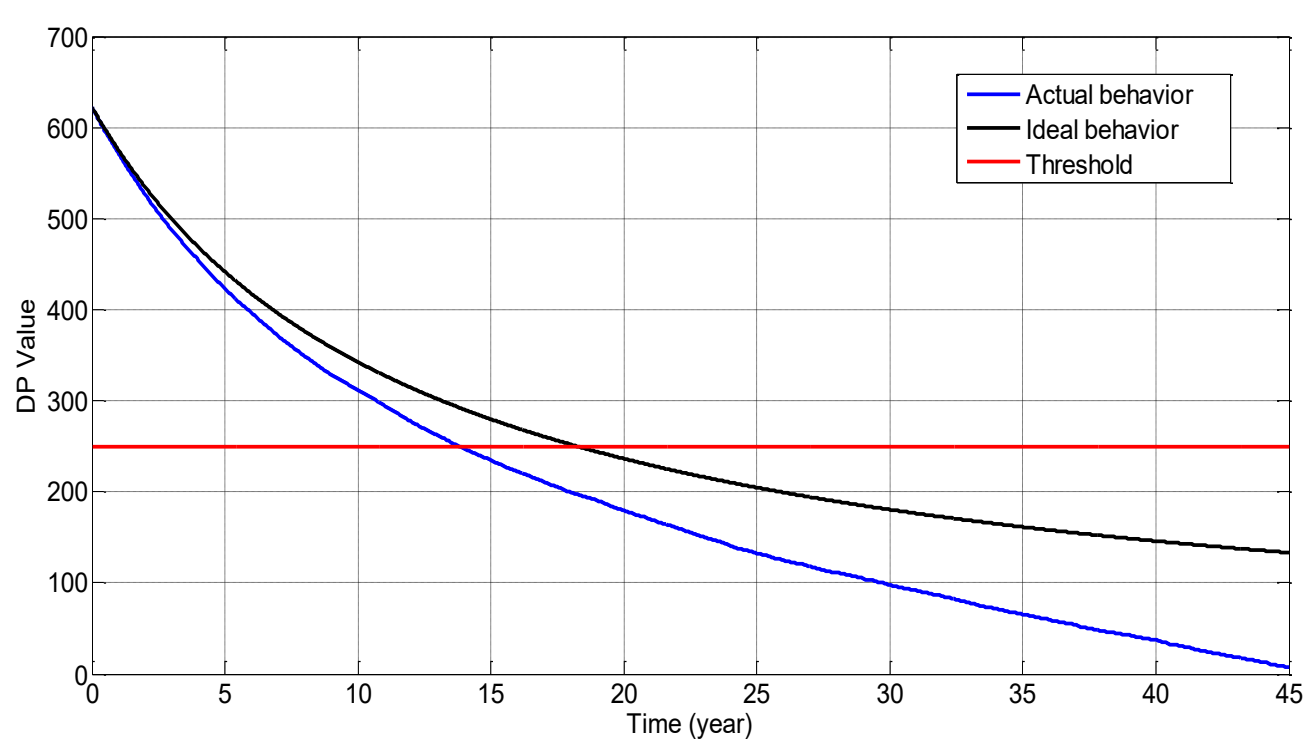

Fig.8. Ideal and actual transformer history curve.

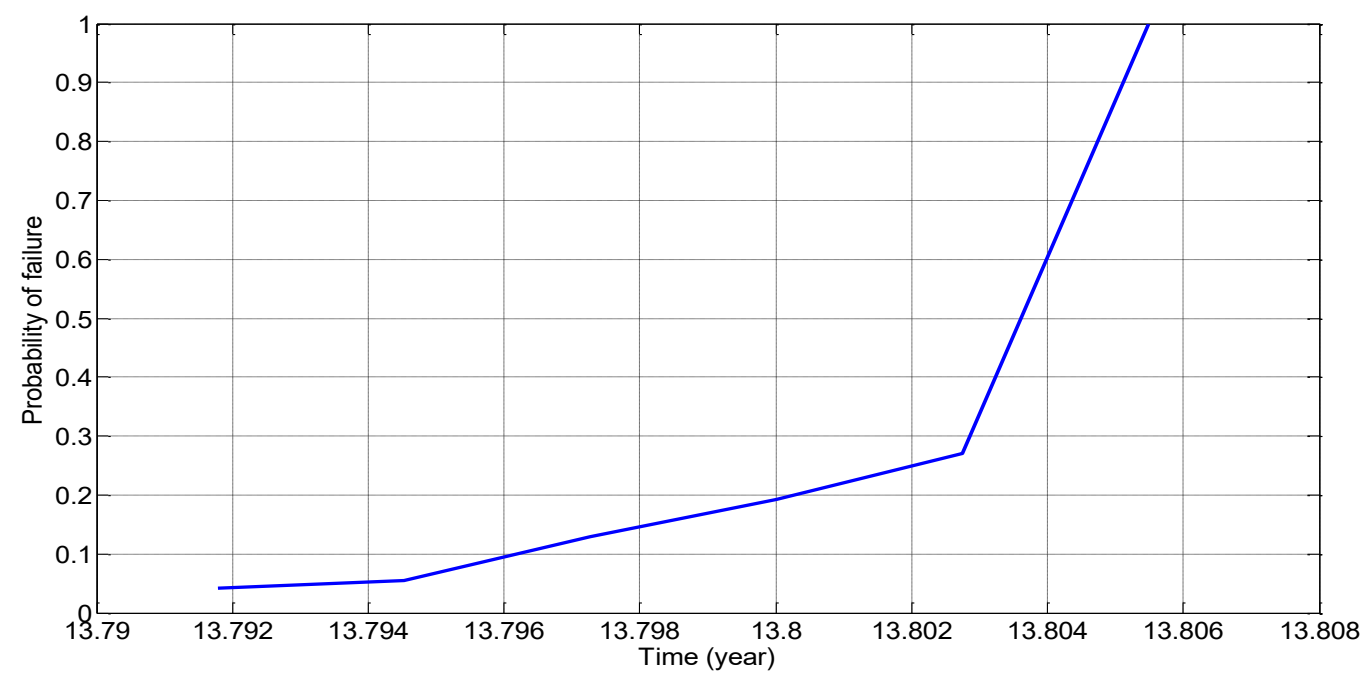

Fig. 9. Failure probability across transformer lifetime.

\subsection{Economic Replacement Time}

In order to determine economic replacement time of transformer, economic valuation of old transformer and new transformer are calculated according to proposed approach which is shown in Fig.1. fig. 10 shows economic valuation of old transformer and new transformer at each year of life time. As can be seen in Fig. 10 economic valuation curve of old transformer intersects economic valuation curve of new transformer in the eleventh year therefore economic valuation of old transformer is less than new transformer after the eleventh year and this year is suitable time to economic replacement time of transformer although, two years remaining to end life of old transformer. 


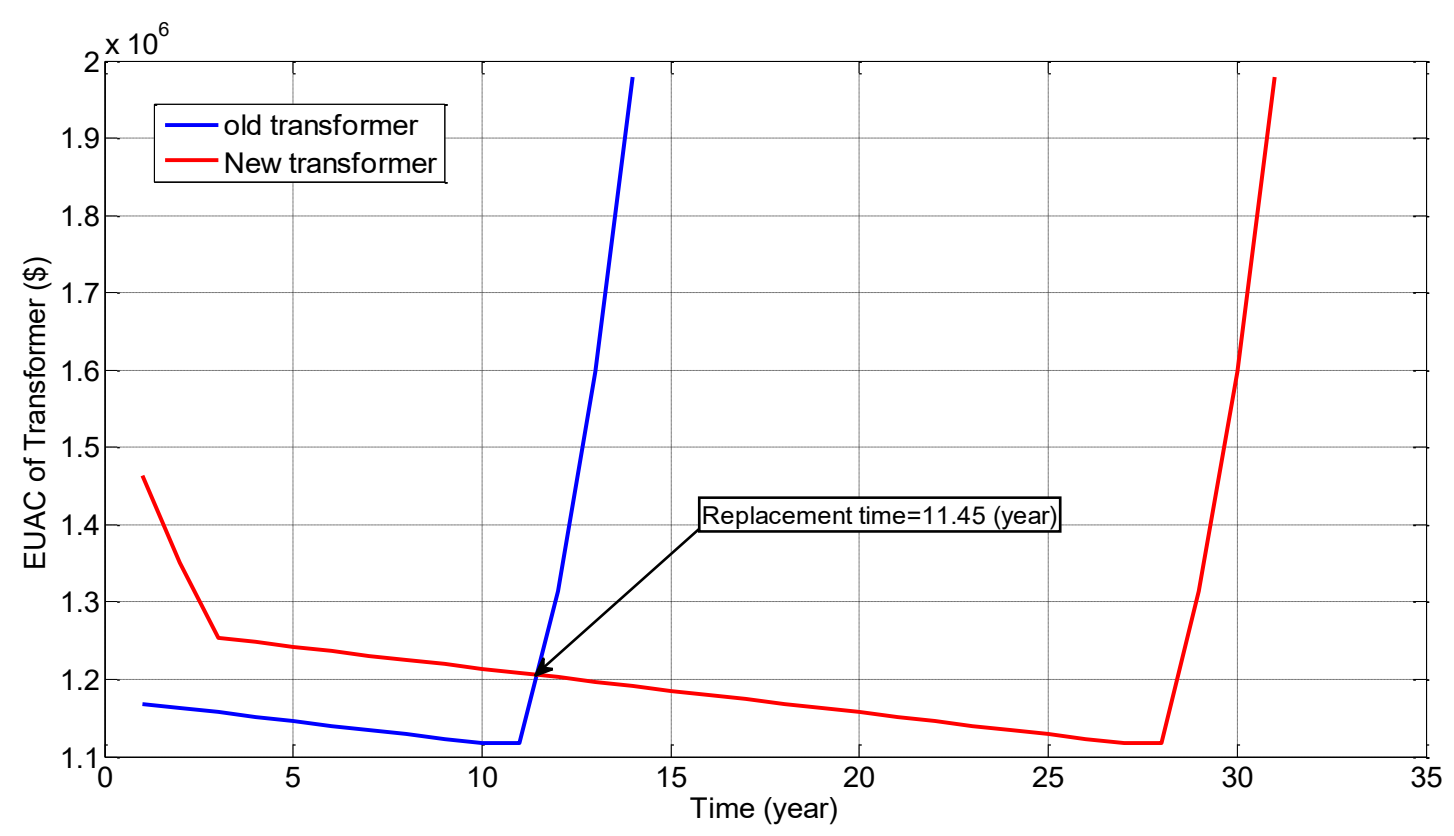

Fig.10. Economic replacement time of old transformer.

\section{CONCLUSION}

A novel approach for estimating economic replacement time of transformer was proposed in this paper. For this purpose at the first step, ANN was used to estimate furfural with high accuracy and low cost. After that, utilizing Monte Carlo algorithm end life of transformer was estimated when health history of transformer had been considered by Pareto distribution at each year of operation. In next step, an economic approach was applied which considers all effective parameters of economic valuation of transformer to estimate economic replacement time of transformer. In this approach economic valuation of old transformer and new transformer are compared at each time of operation. Finally, proposed method was tested on a sample transformer. simulation results show proposed method is a more practical and high precision method for estimating life time and economic replacement time of transformer since it considers all technical and economic factors of operation.

\section{REFERENCES}

[1] Abu-Elanien, A. E. and M. Salama (2010). "Asset management techniques for transformers." Electric power systems research 80(4): 456-464.

[2] Abu-Elanien, A. E., M. Salama and R. Bartnikas (2011). "A techno-economic method for replacing transformers." Power Delivery, IEEE Transactions on 26(2): 817-829.

[3] Bartnikas, R. (1994). "Engineering Dielectrics Volume III Electrical Insulating Liquids."

[4] Bowman, M. S. (1999). Applied economic analysis for technologists, engineers, and managers, Prentice Hall.

[5] Brown, R. (2002). "Electric power distribution reliability. 2002." North Carolina, USA.

[6] Brown, R. E. (2008). Electric power distribution reliability, CRC press. 
[7] DeGarmo, E. P., W. G. Sullivan and J. A. Bontadelli (1979). Engineering economy, Macmillan New York.

[8] Ghunem, R. A., K. Assaleh and A. H. El-Hag (2012). "Artificial neural networks with stepwise regression for predicting transformer oil furan content." Dielectrics and Electrical Insulation, IEEE Transactions on 19(2): 414-420.

[9] Islam, S. M., P. R. Jota and M. Stace (1998). Detection of oil-paper equilibrium moisture content in power transformers using hybrid intelligent interpretation of polarisation spectrums from recovery voltage measurements. Electrical Insulation, 1998. Conference Record of the 1998 IEEE International Symposium on, IEEE.

[10] Jardini, J. A., H. P. Schmidt, C. Tahan, C. C. de Oliveira and S. U. Ahn (2000). "Distribution transformer loss of life evaluation: a novel approach based on daily load profiles." Power Delivery, IEEE Transactions on 15(1): 361-366.

[11] Jirutitijaroen, P. and C. Singh (2004). "The effect of transformer maintenance parameters on reliability and cost: a probabilistic model." Electric power systems Research 72(3): 213-224.

[12] Kachler, A. J. (2005). "Aging of cellulose at transformer service temperatures. Part 1: Influence of type of oil and air on the degree of polymerization of pressboard, dissolved gases, and furanic compounds in oil." Electrical Insulation Magazine, IEEE 21(2): 15-21.

[13] Kurtz, M. (1984). Handbook of engineering economics: guide for engineers, technicians, scientists, and managers, McGraw-Hill.

[14] Lelekakis, N., D. Martin and J. Wijaya (2012). "Ageing rate of paper insulation used in power transformers Part 2: Oil/paper system with medium and high oxygen concentration." Dielectrics and Electrical Insulation, IEEE Transactions on 19(6): 2009-2018.

[15] Li, W. (2013). Reliability assessment of electric power systems using Monte Carlo methods, Springer Science \& Business Media.

[16] Li, W., E. Vaahedi and P. Choudhury (2006). "Power system equipment aging." Power and Energy Magazine, IEEE 4(3): 52-58.

[17] Modarres, M. (1992). What every engineer should know about reliability and risk analysis, CRC Press.

[18] Muthanna, K. T., A. Sarkar, K. Das and K. Waldner (2006). "Transformer insulation life assessment." Power Delivery, IEEE Transactions on 21(1): 150-156.

[19] Newnan, D. G., T. Eschenbach and J. P. Lavelle (2004). Engineering economic analysis, Oxford University Press.

[20] Retterath, B., S. Venkata and A. A. Chowdhury (2005). "Impact of time-varying failure rates on distribution reliability." International Journal of Electrical Power \& Energy Systems 27(9): 682-688.

[21] Sen, P., S. Pansuwan, K. Malmedal, O. Martinoo, M. Simoes and K. Butler-Purry (2011). "Transformer Overloading and Assessment of Loss-of-Life for Liquid-Filled Transformers." Power Systems Engineering Research Center. 
[22] Starr, T., B. Dakin, P. McMahon, P. Harrold and C. Densley (1979). Engineering dielectrics volume I Corona measurement and interpretation. Engineering Dielectrics Volume I Corona Measurement and Interpretation, ASTM International.

[23] Van Bolhuis, J., E. Gulski and J. Smit (2002). "Monitoring and diagnostic of transformer solid insulation." Power Delivery, IEEE Transactions on 17(2): 528-536.

[24] Wang, M., A. Vandermaar and K. D. Srivastava (2002). "Review of condition assessment of power transformers in service." Electrical Insulation Magazine, IEEE 18(6): 12-25.

[25] Wouters, P. A., A. Van Schijndel and J. M. Wetzer (2011). "Remaining lifetime modeling of power transformers: individual assets and fleets." Electrical Insulation Magazine, IEEE 27(3): 45-51. 